\title{
Asbestosis and small cell lung cancer in a clutch refabricator
}

\author{
Jeffrey L Levin, Michael F O’Sullivan, Carolyn J Corn, M Glenn Williams, \\ Ronald F Dodson
}

\begin{abstract}
Objectives-To present a case of asbestosis and small cell lung cancer caused by asbestos in a clutch refabricator.

Methods-Exposed surfaces of used clutches similar to those refabricated in the worker's workplace were rinsed, and the filtrate analysed by analytical transmission electron microscopy. Tissue samples were also analysed by this technique. Results-Numerous chrysotile fibres of respirable dimensions and sufficient length to form ferruginous bodies (FBs) were detected from rinsed filtrates of the clutch. Bronchoalveolar lavage fluid contained many FBs, characteristic of asbestos bodies. Necropsy lung tissue showed grade 4 asbestosis and a small cell carcinoma in the right pulmonary hilum. Tissue analysis by light and analytical electron microscopy showed tissue burdens of coated and uncoated asbestos fibres greatly exceeding reported environmental concentrations ( $3810 \mathrm{FBs} / \mathrm{g}$ dry weight and 2080000 structures $\geqslant 0.5 \mu \mathrm{m} / \mathrm{g}$ dry weight respectively). $72 \%$ Of the cores were identified as chrysotile.

Conclusions-Clutch refabrication may lead to exposure to asbestos of sufficient magnitude to cause asbestosis and lung cancer.

(Occup Environ Med 1999;56:602-605)
\end{abstract}

Keywords: chrysotile asbestos; ferruginous bodies; electron microscopy; lung cancer; asbestosis

Department of Occupational Health

Sciences

J L Levin

Department of Cell

Biology and

Environmental

Sciences, University of

Texas Health Center,

Tyler, TX, USA

M F O'Sullivan

C J Corn

M G Williams

R F Dodson

Correspondence to: Dr Jeffrey L Levin, The University of Texas Health Center, 11937 US Highway 271, Tyler, Texas 75708-3154, USA. Telephone 001903877 5900; fax 0019038777982 ; email levin@uthct.edu

Accepted 17 May 1999
The use of asbestos as a friction product in vehicles constitutes only a fraction of the total consumption of asbestos containing materials used in our society. Although no one would argue its historically important role in vehicle safety, the recognition that exposure to asbestos carries a risk of disease has prompted questions as to fibre emissions from such sources.

Attention to such emissions has primarily focused on release during vehicle operations with most of these studies focusing on brake emissions. ${ }^{1-3}$ Jacko et al concluded that $99.7 \%$ of the emitted asbestos was converted to olivine or forsterite particles. ${ }^{1}$ Williams and Muhlbaier used an enclosed brake testing machine to test emissions from automobile brakes. ${ }^{3}$ They concluded that, although asbestos in such friction products constituted a minor fraction of ambient asbestos concentrations, there may be noticeable increases in asbestos concentrations near high braking areas such as tollbooths. The work of Jaffrey in such real life environments confirmed measurable increases in asbestos due to frequent braking. ${ }^{2}$

Rodelsperger et al measured asbestos fibre concentrations in the air during brake repair. ${ }^{4}$ Analysis by scanning electron microscopy showed concentrations of chrysotile fibres which were considerably higher than measurements by light microscopy. Rood and Scott analysed airborne chrysotile asbestos in a workplace making clutches and brake shoes. ${ }^{5}$ Their observations by transmission electron microscopy indicated that only between a fifth to a half of fibres longer than $5 \mu \mathrm{m}$ would have been visible by optical microscopy, and in their samples, all fibres were of respirable dimensions.

Publications on the potential for exposure to asbestos used in automotive friction products is, therefore, limited to data from sampling in areas of manufacturing processes or in areas adjacent to repetitious braking. There are few data available on exposures after use or during refabrication particularly when this process involves clutch components. ${ }^{6}$

In the present report, material easily freed from worn clutches such as those used in the workplace in question were analysed. The worker's illness attributed to exposure to asbestos from refabricating clutches is discussed, with ultrastructural analysis of lung tissue and clutch surface extracts.

\section{Clinical case history}

A 59 year old man was admitted to hospital with a 1 month history of persistent cough and progressive dyspnoea. A chest radiograph on admission showed focal consolidation in the right upper lobe, a coarse, diffuse interstitial pattern most notable at the bases and bilateral apical pleural scarring. The patient had smoked one to one and a half packs of cigarettes a day for 35-40 years. The most notable element of his occupational history was work as a clutch rebuilder and sorter from 1966 to 1990 . He drilled rivets from clutches to remove the used facings from the plates. He lived on a small rural farm.

Physical examination showed coarse rales. Pulmonary function studies showed markedly reduced lung volumes and diffusion capacity, accompanied by obstruction. Skin testing and sputum analysis were negative for evidence of tuberculosis. Fibreoptic bronchoscopy produced washings with many ferruginous bodies (FBs) consistent with asbestos bodies. Transbronchial biopsy of the right upper lobe showed alveolar septal fibrous thickening and an alveolar inflammatory cell infiltrate including macrophages (some multinucleate and of 
giant cell proportions) and eosinophils. No acid fast bacilli or fungi were detected. No well defined granulomata or classic viral inclusions were found.

The patient was diagnosed with eosinophilic pneumonitis and asbestosis and responded to initial treatment of his eosinophilic infiltrate with bronchodilators and high dose corticosteroids. After discharge, however, he became gradually more dyspneic with weight loss. $\mathrm{He}$ was readmitted with severe hypoxaemia. Clubbing was noted and a chest radiograph showed right hilar enlargement. Computerised tomography (CT) of the chest showed a large right hilar mass and confirmed severe interstitial fibrosis. A CT guided biopsy of the mass showed a small cell undifferentiated carcinoma.

The procedure was complicated by a pneumothorax. Despite chest tube placement and initiation of chemotherapy, the patient died of respiratory failure.

Necropsy findings of the respiratory system showed: (a) severe, bilateral, interstitial pulmonary fibrosis with asbestos bodies and with honeycombing, most pronounced beneath the pleural surfaces and at the bases (grade 4

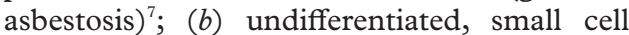
carcinoma at the right lung hilum with intrapulmonary, right diaphragmatic, and mediastinal lymph node metastasis. Formalin fixed lung tissue was sampled at random sites and analysed by light and electron microscopy.

\section{Methods}

ANALYSIS OF CLUTCH MATERIAL

Clutches similar to those that had been refabricated in the worker's workplace were analysed for friable or loose material as might be expected to become airborne in the workplace.

Exposed surfaces were rinsed with $100 \mu \mathrm{l}$ prefiltered water and this washing was collected in a sample vial. Six such clutch pads were sampled in a similar manner. Each rinse aliquot was increased to about $10 \mathrm{ml}$. The

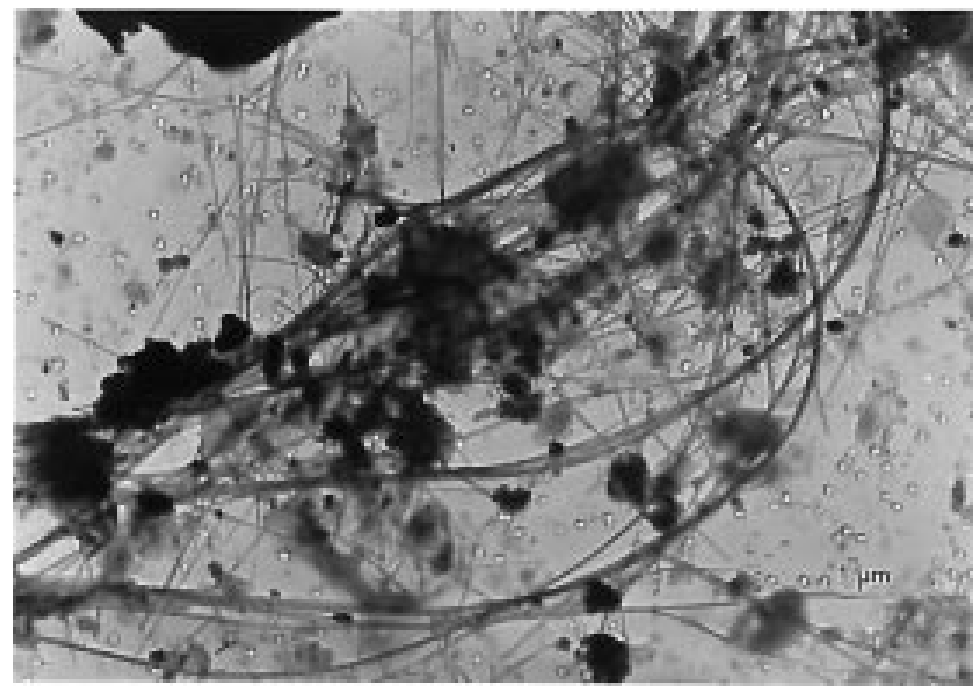

Figure 1 A clump of material collected by gentle washing of the surface of the used clutch face shows the presence of complex chrysotile bundles as well as very long chrysotile structures. Bar $=1.0 \mu \mathrm{m}$. sample was gently swirled after which half of the volume was filtered through a $25 \mathrm{~mm}$ diameter polycarbonate (Nucleopore) filter with a pore size of $0.2 \mu \mathrm{m}$. The filter surface and the surface particulates were coated with evaporated carbon and the filter matrix was dissolved with chloroform. The carbon replicas were examined at magnifications of up to $50000 \times$ in a JOEL $100 \mathrm{CX}$ analytical transmission electron microscope (ATEM) equipped with an EDAX NX-2 $x$ ray energy analyser.

ANALYSIS OF TISSUE

Formalin fixed lung tissue was analysed for particulate burden. Lung tissue was processed, embedded in paraffin, and haematoxylin and eosin stained sections were evaluated by light microscopy. Additional lung tissue was dissected, pooled, and prepared for particulate analysis by a digestion procedure developed in our laboratory. ${ }^{8}$ Samples of the pooled digest were filtered through mixed cellulose ester filters (Millipore) for light microscopy assessment for the presence of FBs. A quarter wedge of each filter was screened at $\times 200-400$ magnification with an $\mathrm{AO}$ microstar microscope.

Aliquots of the pooled sample were evenly distributed on a $0.2 \mu \mathrm{m}$ pore size polycarbonate filter (Nucleopore), filtered, and carbon replicas were made. The area scanned in each replica was assessed at $\times 20000$ for fibres $\geqslant 0.5 \mu \mathrm{m}$. An additional scan at $\times 600-1200$ was carried out to locate FBs which were analysed for core composition.

\section{Results}

\section{CLUTCH ANALYSIS}

Numerous bundles and separated fibres of chrysotile asbestos were seen on ATEM (fig 1). Confirmation of fibre identity as chrysotile was done by energy dispersive $x$ ray analysis (fig 2), and selected area diffraction. The samples contained numerous respirable sized chrysotile fibres including many which were of sufficient length $(\geqslant 8 \mu \mathrm{m})$ to form FBs if inhaled.

TISSUE ANALYSIS

Ferruginous bodies consistent with asbestos bodies were found in regions of fibrosis and inflammation fulfilling pathological criteria for asbestosis. $^{7}$

The number of isolated FBs consistent with asbestos bodies were counted by light microscopy as being $3810 \mathrm{FBs} / \mathrm{g}$ dry weight. This concentration clearly exceeds those found in people with environmental exposures. ${ }^{9}$

Light microscopy allows for FBs to be identified as asbestos bodies with a high level of accuracy. However, it is not possible by light microscopy to determine the type of asbestos core. Electron microscopy was used for this purpose. More than $72 \%$ of the cores of analysed FBs were chrysotile asbestos (fig 3). Nine per cent of the ferruginous body cores were amosite and $9 \%$ were tremolite. The remaining FBs were totally coated, and, therefore, could not be analysed for core composition.

The uncoated asbestos fibres were found as both bundles (fig 4) and more isolated 
chrysotile fibres. At lower magnification scan (which emphasised longer fibres), there were 1216000 structures/g dry weight of lung

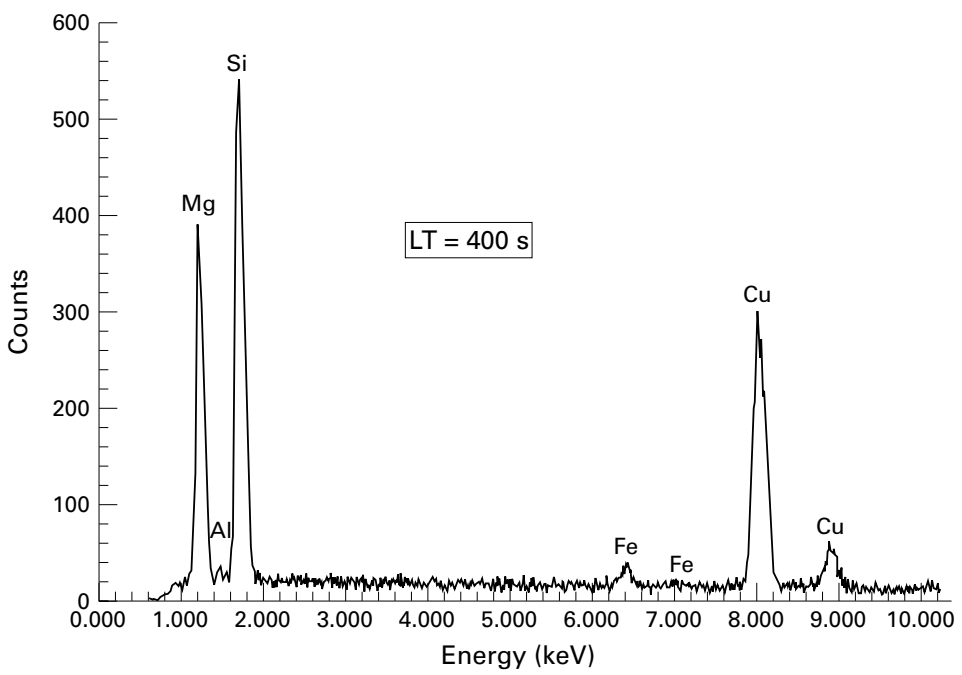

Figure $2 x$ ray energy dispersive analysis confirms clutch washing fibre identity as chrysotile. $L T=$ Live time to acquire the spectrum.

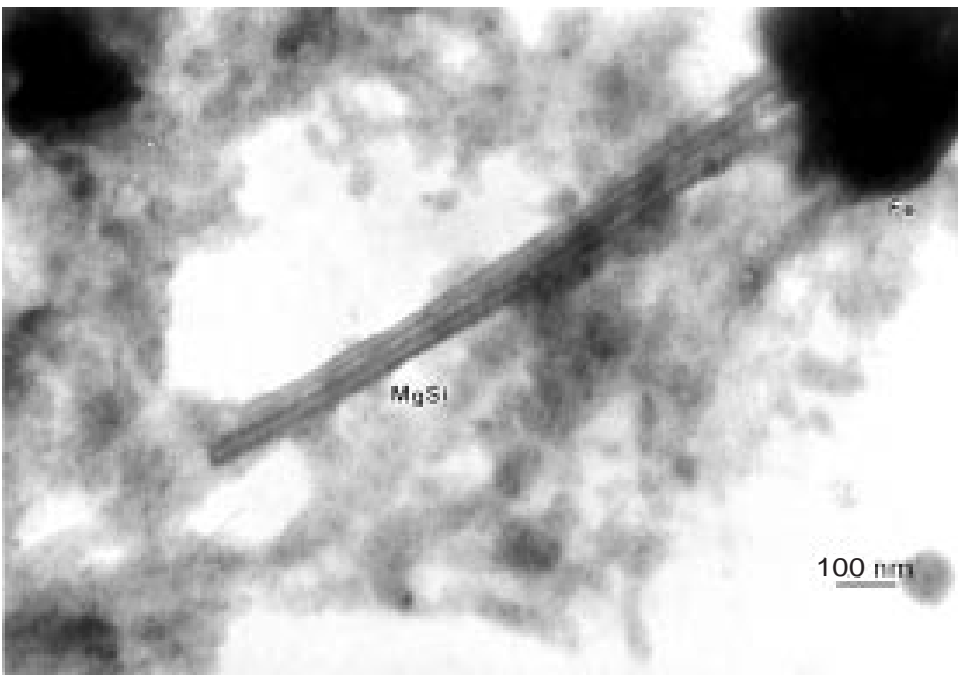

Figure 3 The chrysotile core of this ferruginous body $(\mathrm{Fe})$ from the worker in question can be identified by the protruding fibril (MgSi) and its characteristic tubular structure.

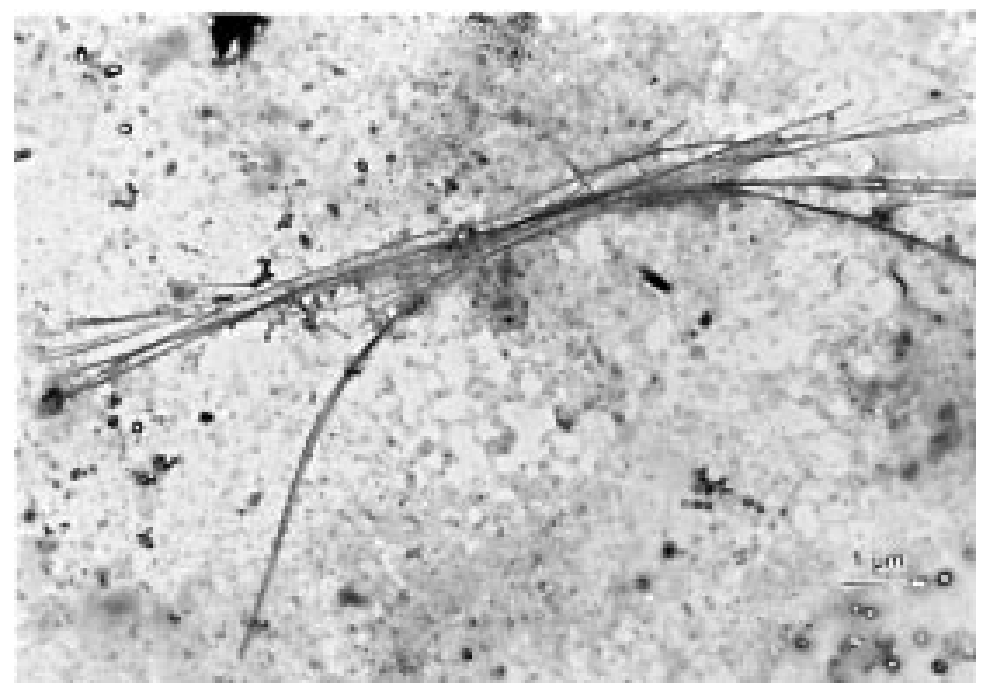

Figure 4 A large cluster of long chrysotile fibres collected from the worker's lung. tissue. When the higher magnification ( $\times 20000)$ was used, the number of structures rose to 2080000 structures/g dry weight (due to inclusion of shorter fibres $(\geqslant 0.5 \mu \mathrm{m})$ ). The only type of uncoated asbestos fibre found in the scanned area was chrysotile. Uncoated chrysotile fibres were composed of short fibres $(\leqslant 5 \mu \mathrm{m})$ as well as considerably longer fibres (up to $44 \mu \mathrm{m}$ ). It should also be recognised that in this unique exposure many of the longer inhaled chrysotile structures were within the cores of FBs (which are only formed on fibres $>8 \mu \mathrm{m}$ in length).

Either of these measurements of tissue fibre burden exceed those expected to result from environmental exposure, ${ }^{9}$ especially from the East Texas region where the man lived. ${ }^{10}$

\section{Conclusions}

This case has many unique features. The limited published data deal with exposure to asbestos from automotive friction components either in the initial manufacturing or in the use phases, and these are mainly found on studies of brake components and not material associated with clutches. ${ }^{1-35}$ Few studies exist about exposure to friction products of asbestos during maintenance or repair after use. ${ }^{411}$ There are case reports of pleural mesothelioma diagnosed in a laundry owner handling washing machine clutches ${ }^{6}$ and in a brake repair worker. ${ }^{12}$ In both cases, the presence of chrysotile asbestos in the lung tissue was confirmed by electron microscopy and energy dispersive analysis. The man in the present report was exposed to the components of clutches after use, an area devoid of published data.

It is a valid observation that without air sampling, there is no way to measure airborne exposures in the workplace. As is the case with many exposures of the type which this particular worker sustained, such monitoring information does not exist. However, based on the data in the present report, chrysotile asbestos of respirable size was found in a friable condition on the clutches analysed. These types of materials from clutches were handled in the work environment in the refabrication process. Furthermore, the analysis of lung tissue showed the same types of fibres of the same dimensions as identified on the clutch components. It seems reasonable, therefore, to extrapolate that the characteristics of the chrysotile fibre burden in tissue (made up of many fibres $\geqslant 5 \mu \mathrm{m}$ in length) reflect a unique occupational exposure, as chrysotile found in the tissue from environmentally exposed people, both in our laboratory and in the scientific literature, is predominantly made up of short fibres ( $\leqslant 5 \mu \mathrm{m}$ in length). The finding of a small percentage of amphibole fibres is not entirely unexpected in people with exposure to chrysotile from any source, and in this case, could also have arisen from other unidentified exposures. None the less, the chrysotile fibre burden certainly predominates in this case.

A documentation of the type of material used in the clutches (chrysotile) and of the presence of respirable potential of this fibrous portion was made through electron 
microscopy. The diagnosis of asbestosis was made with established pathological criteria. ${ }^{7}$ The exposure to respirable chrysotile as found in this case, combined with the identification of fibrosis and coated chrysotile fibres (FBs) shows the risk that chrysotile posed for asbestosis and associated lung cancer in this clutch rebuilder. A recent review of exposure to chrysotile supports this finding, and conclusions about the relation between chrysotile and cancer risk are stated as: " 1 ) there is strong evidence that chrysotile is associated with an increased risk of lung cancer and 2) chrysotile may be less potent than some amphiboles for inducing mesotheliomas, but there is little evidence to indicate lower lung cancer risk." 13

1 Jacko MG, Ducharme RT, Somers JH. Brake and clutch emissions generated during vehicle operation. New York: Sociemissions generated during vehicle operati
ety of Automotive Engineers, 1973 .

2 Jaffrey SAMT. Environmental asbestos fibre release, from brake and clutch linings of vehicular traffic. Ann Occup Hyg 1990;34:529-34.

3 Williams RL, Muhlbaier JL. Asbestos brake emissions. Environ Res 1982;29:70-82.
4 Rodelsperger K, Jahn H, Bruckel B, et al. Asbestos dust exposure during brake repair. Am f Ind Med 1986;10:6372

5 Rood AP, Scott RM. Size distributions of chrysotile asbestos in a friction products factory as determined by transmission electron microscopy. Ann Occup Hyg 1989;33:583-90.

6 Levin JL, Stocks JM, Shepherd JR, et al. Asbestos exposures: known and underrecognized sources [letter]. Am F Ind Med 1992;22:607-8

7 Craighead JE, Abraham JL, Churg A, et al. The pathology of asbestos-associated diseases of the lungs and pleural cavities: diagnostic criteria and proposed grading schema. Arch Pathol Lab Med 1982;106:544-96.

8 Williams MG, Dodson RF, Corn C, et al. A procedure for the isolation of amosite asbestos and feruginous bodies from lung tissue and sputum. F Toxicol Environ Health 1982;10:627-38.

9 Hammar SP, Dodson RF. Asbestos. In: Dail DH, Hammar SP, eds. Pulmonary pathology, 2nd ed. New York: SpringerVerlag, 1994:901-83.

10 Dodson RF, Williams MG, Huang J, et al. Tissue burden of asbestos in non-occupationally exposed individuals from East Texas. Am f Ind Med 1999;35:281-6.

11 Rohl AN, Langer AM, Wolff MS, et al. Asbestos exposure during brake lining maintenance and repair. Environ Res 1976;12:110-28.

12 Langer AM, McCaughey WTE. Mesothelioma in a brake repair worker. Lancet 1982;ii:1101-3.

13 Stayner LT, Dankovic DA, Lemen RA. Occupational exposure to chrysotile asbestos and cancer risk: a review of the amphibole hypothesis. Am F Public Health 1996;86:179-86. 